\title{
The Soviet Skyscraper: Take-Off and Landing
}

\author{
By François Blanciak
}

\begin{abstract}
Reviewing a number of radical designs for skyscrapers by Russian Constructivist architects operating in the 1920s, the paper researches how the notion of weightlessness can be identified as a common denominator to many of these projects, how this characteristic aspect manifested itself in architectural form, and what was the cultural framework at play in the definition of this paradigm. Specifically, the paper studies the design strategies of Lazar Khidekel, Georgy Krutikov, Viktor Kalmykov, and most importantly Ivan Leonidov, to highlight their collective desire to leave the ground, either through morphological suggestion or literally, relating them to the historical context of space exploration as a political pursuit. It also delves into the theoretical influences of this particular architectural ethos, looking into the work of Cosmist philosopher Nikolai Fedorov for what may have inspired these architects to design seemingly weightless structures. Finally, the paper searches for parallels such designs have made, wittingly or not, with actual space exploration devices, and investigates to what extent these experimental projects have eventually found ground in the "West."
\end{abstract}

\section{Introduction}

Architecture is fundamentally supposed to be anchored in the ground. Its objects are expected to remain static. Yet, a number of projects by Russian Constructivist architects operating in the 1920s set out to undo this fundamental connection, devising schemes which often attempted to escape gravity. What is researched in this paper is how this characteristic aspect manifested itself in architectural form, and what was the cultural framework at play in the definition of this paradigm. The design strategies of Lazar Khidekel, Georgy Krutikov, Viktor Kalmykov, and Ivan Leonidov will be reviewed in order to highlight by which means their collective desire to leave the ground was architecturally expressed, either through morphological suggestion or literally, relating them to the historical context of space exploration as a political pursuit. As the idea of reaching for the sky can be seen as a more general preoccupation of early twentieth-century Russian culture, this study will research contemporary literature which focused on this theme, and look more specifically into the work of Cosmist philosopher Nikolai Fedorov for what may have inspired these architects to design seemingly weightless structures. Following a comparative mode, the paper also searches for parallels such designs have made, wittingly or not, with space exploration devices, and investigates to what extent these projects have eventually found ground in the "West," looking for clues of the influence of Constructivist projects in the built output of remote countries as a means to precisely relate to their once-contested capacity to fly.

*Senior Lecturer, School of Architecture, Design and Planning, University of Sydney, Australia. 


\section{Weightlessness in Constructivist Architectural Form}

\section{Lifting the Skyscraper}

If the piloti, the cantilever, and the plan libre all indicate that removing the building from the ground was - and remains - a common preoccupation of modern architecture, the most radical expression of this ambition can surely be witnessed in architectural projects that flourished in the Russian Vkhutemas schools of architecture shortly after the Soviet Revolution of 1917. This sense of removal from physical context can be traced to an intimate relationship with the art world of Suprematism, wherein Kazimir Malevich had sought to reduce figures to their most primitive expression, either on canvasses, as in his famed Black Square (1915), or in three dimensions, as in his combinations of white blocks which he called "architectons." The relation of early Soviet experimental architecture to Malevich's expansive work can probably best be grasped in the depiction of Lazar Khidekel's large-scale projects, which articulate a transition between abstract paintings and architectural/urban representations. A student from Marc Chagall, El Lissitzky, and Malevich himself, Khidekel produced a number of schemes in the 1920s for large horizontal buildings and cities which appeared to be floating above ground, latticed urban forms strictly made of perpendicular, elongated blocks and (rarely) circular shapes, in true Suprematist fashion.

With these projects, Khidekel brought forward the idea of vertical zoning, the stratification of architectural program into layers parallel to the ground. The importance he gave to a harmonious relationship between human settlement and the environment led him to minimize the incidence of vertical points of connection with the Earth, which resulted in very large spans, and generous cantilevers. Such designs anticipated the emergence of the hovering city schemes of Constant, Yona Friedman, or Peter and Alison Smithson in 1950s Europe, with the exception that Khidekel's schemes tended to hover above natural-rather than urban-settings, as an attempt to leave landscapes (or water bodies) intact. The idea of the horizontal skyscraper (fully developed by Lissitsky as a prototype for Moscow high-rises in 1923-1925) takes shape in Khidekel's projects, symbolically denying the need to fight against centrality and gravity which the vertical skyscraper embodies, and instead propounding an image of a city detached from the Earth, transformed into a spaceship-like structure. But perhaps these ideas of continuity and horizontality find themselves taken to their most extreme formulation in the lesser-known project of Viktor Kalmykov for a ring city called Saturny (1929) which, emulating the rings of Saturn, proposed to build a structure that simply circles the Earth around its equator without ever touching its surface, ${ }^{1}$ using the planet's gravitational field to maintain the complex into space (Figure 1). Extruded as a few-story high inhabitable building in Kalmykov's visual description, the orbital skyscraper would only be accessed by aircrafts of a new kind.

1. S. O. Khan-Magomedov, Pioneers of Soviet Architecture: The Search for New Solutions in the 1920s and 1930s (trans.) A. Lieven (London: Thames and Hudson, 1987), 283. 


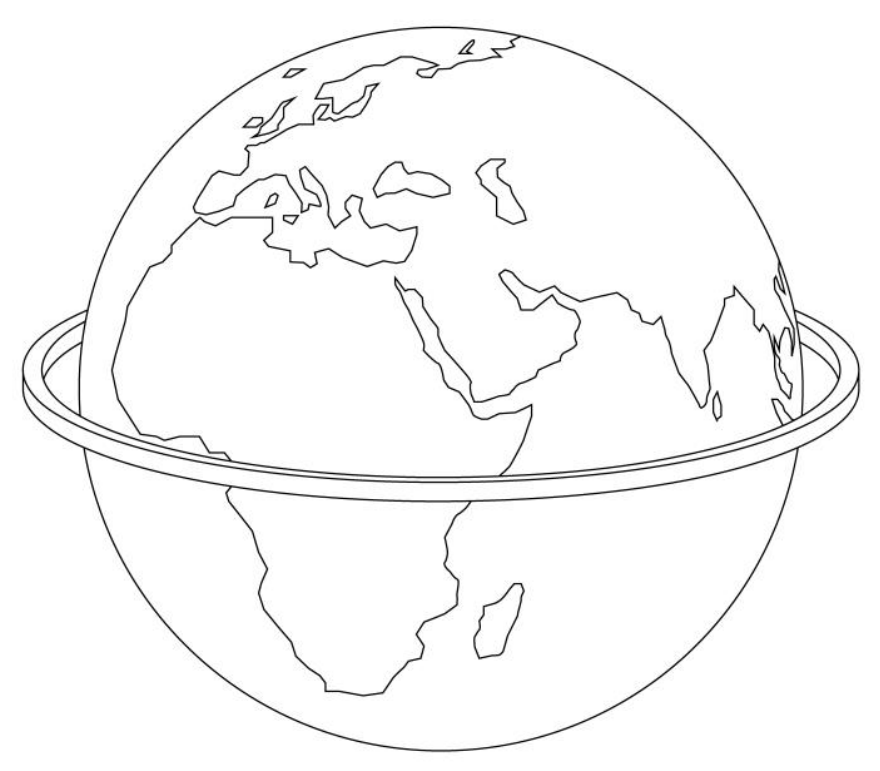

Figure 1. Axonometric Representation of Viktor Kalmykov's Saturny Project Source: Drawing by Author.

Kalmykov's vision could possibly not have been developed without the influence of Georgy Krutikov, whose diploma project of 1928, commonly referred to as the Flying City, and published for the first time by the Russian historian Selim Omarovich Khan-Magomedov forty-five years after its completion as a thesis, synthesized a number of nascent technologies into an experimental and controversial design. Krutikov based his project on a desire to render architecture mobile, gathering that the speed of human transportation, which had been gradually accelerating, needed to be addressed in building design. He likewise defended a protective view of the environment, and mentions "planetary organization" as part of his objectives in his diploma notes. "Obsolete and inconvenient town planning," he wrote in 1929, "must be replaced by flexible planning," 2 which, in turn, should involve the added dimension of height. His Flying City project, or City of the Future, as he named it, aimed to clear the ground of the Earth for the sole purposes of industrial work and leisure, while housing and official buildings would be located in levitating stations, far above. Krutikov's speculations largely depended on his belief in the capacity of nuclear energy to allow for buildings to be sustained in the air in the future.

2. Cited in S. O. Khan-Magomedov, Georgii Krutikov: The Flying City and Beyond (trans.) C. Lodder (Barcelona: Tenov, 2015), 37. 
In his vision, the transition between the several flying cities scattered around the globe, and the surface of the planet itself, would be done by means of flying capsules able to plug into specifically-designed mooring areas around the dwellings (recalling the type of spatial organization materialized in Kisho Kurokawa's design for the Nakagin Capsule Tower in Tokyo decades later). The capsule typology was carefully designed by Krutikov as an aerodynamic vessel devoid of any protruding propellers, enabled to navigate in the air, as well as over and under water, according to his diagrams. Its unique passenger was meant to sit perpendicular to the direction of travel (although he envisioned the capsule's shell as flexible in order to allow for changes in body position), facing a large ovoid window covering most of the largest extremity of the oblong cabin and part of its roof. It was conceived as a shuttle between sky and ground, but also as part of the very accommodation it was to be attached to.

Krutikov's proposal can better be understood when reset in the literary context of its time, which expressed a yearning to reach for the sky, such as exemplified in Vladimir Mayakovsky's long futuristic poem titled The Flying Proletarian (1925), wherein every individual owns and pilots a personal aircraft, eating takes place in "aerocafeterias," and Moscow is transformed into a myriad of airports. ${ }^{3}$ The research that culminated in Krutikov's radical diploma project led him to carefully study aircraft design, and dirigible gondolas in particular, as well as the work of rocket scientist Konstantin Tsiolkovsky, who was closely linked to Cosmism. Khan-Magomedov stressed a possible connection between the two men, adding that "Krutikov knew of Tsiolkovsky's design [an all-metal airship without a carcase, which would have been able to change shape while in flight] and based his own work on this project. He turned for advice to Tsiolkovsky and wrote him several letters." 4

\section{Leonidov's Detachment}

If Ivan Leonidov did not design flying cities per se, his unbuilt architectural and urban planning designs are certainly worth mentioning vis-à-vis the notion of weightlessness in architecture. Between 1927 and 1930, he elaborated a peculiar design vocabulary through a series of projects-namely, the Sov-kino Film Production Complex (1927), the Tsentrosoiuz Building (1928), A Club of New Social Type (1928), the Monument for Christopher Columbus (1929), the House of Industry (1929), the Palace of Culture for the Proletarsky district of Moscow (1930), and the planning for the new town of Magnitogorsk (1930) which all appeared to be, in essence, variants of his diploma project for the Lenin Institute of Librarianship of 1927 (Figure 2). What characterized these designs is a systematic breakdown of the main program of the building into an array of different elements, which alluded to Classicism through a consistent use of "pure" geometric forms (such as pyramids or spheres), coupled with a

\footnotetext{
3. See: V. Terras, Vladimir Mayakovsky (Boston: Twayne Publishers, 1983).

4. Khan-Magomedov, Georgii Krutikov: The Flying City and Beyond, $2015,89$.
} 
scattering of these elements onto the given site. ${ }^{5}$ They also expressed a desire to push the limits of construction technology, thus resulting in contrasting visions of distant past and future. The consequent effect of controlled disorder, in plan, was enhanced by a strict adherence to the principle of orthogonality between all the dispersed volumes of the project. If such principles were already present in a number of Constructivist projects by the time of his intervention, Leonidov not only raised these morphological ideas into rules for his own work, but also added to them the notion of detachment between the different building elements of a single project. For example, in his design for the Lenin Institute, the slender rectangular blocks of the book shelves, reading rooms, and the Institute for Library Sciences barely meet at their extremity, while the spherical auditorium, held in place by cables, touches the ground at a single point, and the four research institutes simply do not connect, resulting in an impression that the building masses virtually flee each other.

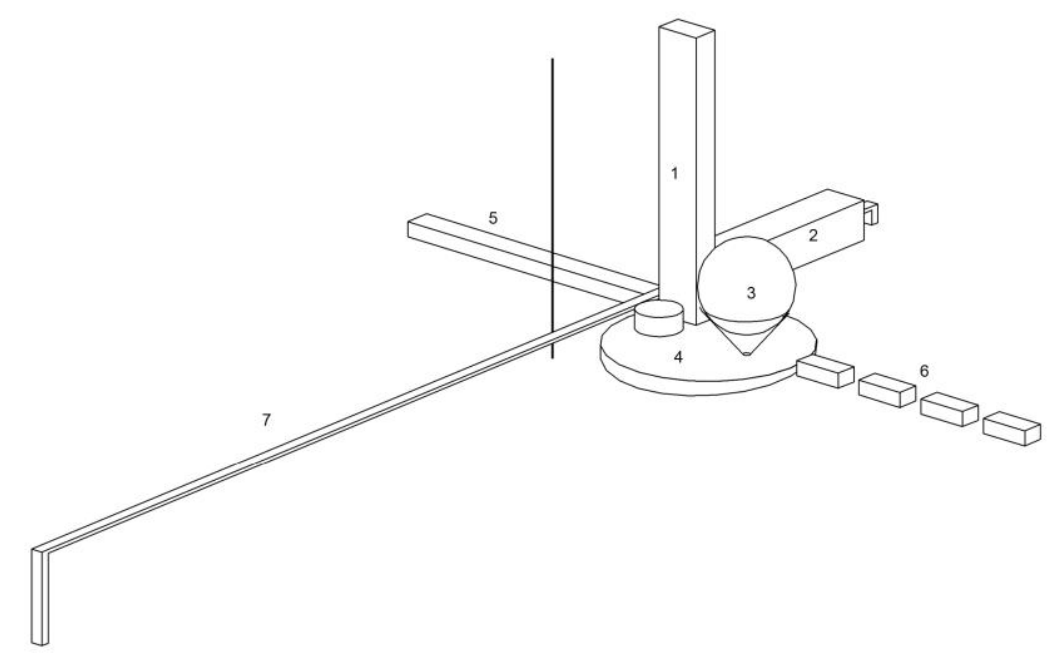

Figure 2. Ivan Leonidov. Lenin Institute of Librarianship, Moscow, 1927 Legend: 1. Library of Fifteen Million Volumes 2. Reading Rooms 3. Auditorium 4. Science Theater 5. Institute for Library Sciences 6. Research Institutes 7. "Aerotram" Source: Drawing by Author.

This aspect of physical detachment stands in sharp contrast with the architectons of Malevich, or the hovering structures of Khidekel, which, despite also comprising forms flowing in different directions orthogonally, still obeyed to a principle of aggregation into a common body. It also recalls the surge of autonomy that Emil Kaufmann theorized (around the same time) around the work of Claude-Nicolas Ledoux. As Kaufmann posited, the French Revolutionary architect innovated in parting from the Baroque enchaînement (which demanded that all building parts submit to a greater, figurative whole), and opted instead for a

5. F. Blanciak, "Revolutionary Objects: Pure Forms and Disorder in Ivan Leonidov's Work," Journal of Civil Engineering and Architecture 8, no. 2 (2014): 139. 
dissociation of the main building volume into separate entities, ${ }^{6}$ likewise negating the traditional aggregative role of architecture. If Ledoux indulged in drawing planets revolving around the sun (as in his "elevation" of the cemetery of the town of Chaux, France, of 1804), Leonidov's essential inclusion of void as an integral part of architecture can be interpreted as a desired relation to cosmic space. Indeed, most emblematic of his drawings for these projects was also his repetitive use of black as a background - as if his designs were to find home in the dark matter of Malevich's representations of the cosmos - for the thin white lines that defined masses and materials in both plan and elevation, an unusual technique at that time. In Leonidov's design, the notion of movement is utilized to create the presence of space. Weightlessness, it might be worth noting in this respect, is not devoid of rules. It induces the centers of gravity of bodies in space to follow straight lines. It also denies attraction to a common centre (Figure 3). These two characteristics can be found in his projects of the 1920s.

1.

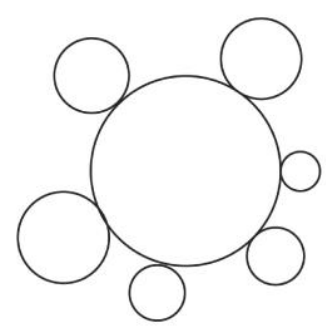

Figure 3. Grouping Patterns of Elements Exposed to Different Gravitational Values 1. Gravitation (Contact to a Main Element) 2. Weightlessness (No Main Element, No Contact).

Source: Drawing by Author.

The concept of weightlessness in Leonidov's composition (or, rather, decomposition) techniques can be observed not only in plan, but also in elevation. His late work indeed includes a project called The City of the Sun-named after Tomaso Campanella's eponymous novel of 1602-which denotes this characteristic trait. He worked on this project from his return from war until his death in 1959, and appears to have used this project as a source of inspiration for several projects, or variants, including a headquarter complex for the United Nations and the Moscow World's Fair. The City of the Sun is more a gathering of individual buildings than an exercise in strict city planning. Its imaginary site was an island in the Indian Ocean. What distinguishes this project is the striking diversity of building forms and sizes, each one aiming to embrace the traditional and cultural specificities of the respective nations they represent, a message of

6. See: E. Kaufmann, De Ledoux à Le Corbusier: Origine et Développement de l'Architecture Autonome (trans.) Guy Ballangé (Paris: La Villette, 2002). 
tolerance on par with Campanella's book, which imagined a city based on principles of egalitarianism reminiscent of communist ideals. Reflecting on this project, Jacques Herzog wrote that Leonidov "explored gravity as a weighty historical vehicle that he attempted to overcome."7 Relieving society from the weight of the past appears to be the symbolic dimension Leonidov tried to assign to the floating dimension of this project, invoking a new type of social organization that fosters world peace by tolerating the formal and cultural specificities of each individual nation. Left as an incomplete project, The City of the Sun was represented only through perspective views. In contrast with his earlier projects, plans and sections are absent. However, after working on a number of neo-classical designs in the 1930s and 1940s, for which he used the most conventional means of architectural representation, Leonidov renewed in this project not only with the pure forms that have characterized his earlier work of the 1920s, but also with sheer black as backdrop for the buildings he depicted, referring again to cosmic darkness.

1.

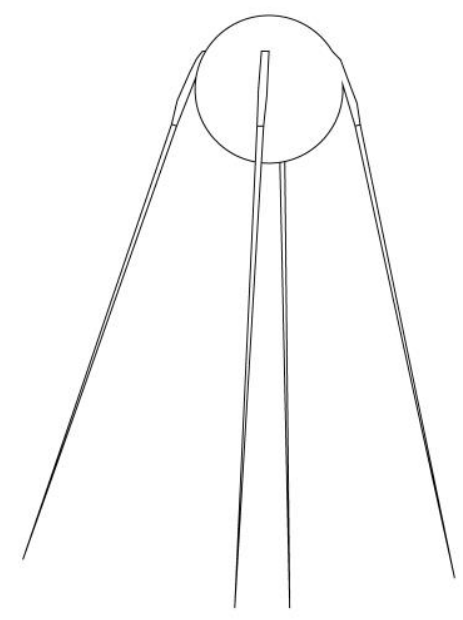

2.

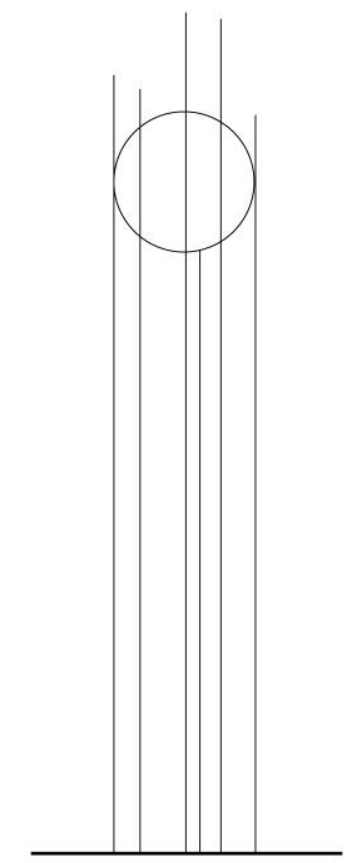

Figure 4. 1. Sputnik 1 (in Vertical Position), Launched on October 4, 19572. Ivan Leonidov. Tower Design for The City of the Sun, 1943-1958 Source: Drawing by Author.

The microcosm envisioned by Leonidov was intended to recall a solar system. The City of the Sun and its derivative projects all contain an array of buildings, but one stands out as a common object: a tall tower consisting of a

7. J. Herzog and P. De Meuron, Treacherous Transparencies (New York: Actar, 2016), 23. 
large golden globe hovering in the sky, merely attached to the ground by what looks like thin parallel columns of unequal heights, which make this building design in elevation strikingly resemble Sputnik 1 (the first made-made satellite to be put into orbit), also a sphere on long stilts, mainly used to keep the object flying in the right direction (Figure 4). It is difficult to think that he would not have been aware of this connection, as Sputnik 1 became a mass media phenomenon shortly after its successful launch in 1957, while he was working on this project. He also himself designed a monument to the first Sputnik in 1957-58 (which did not look like the satellite, but rather resembled a mountain). What is meant here is not that Leonidov's project preceded the satellite, nor the opposite, but that the common desire to use technology for the design of flying (or hovering) objects led both rocket scientists and Constructivist architects to similar results (in fact, the capsule which famously carried the first earthling - a stray dog called Laika - in outer space with Sputnik 2 also bears resemblance to Krutikov's highly idealized space travel cabin in both form and functionality).

This endeavour to at once embrace and challenge technological development led Leonidov early on to exhort his fellows: "Architects!" he wrote in the Russian journal Sovremennaia Arkhitektura in 1926, "Do not imitate the forms of technology, but learn the method of the engineer designer." A number of other projects by Leonidov turned out to be at the forefront of construction techniques. For example, his design for the Headquarters Building for the Commissariat of Heavy Industry in Moscow (1934) makes use of the form of the hyperboloid for a tall structure, which nearly coincided with the first implementations of this type of structures in the design of power plant cooling towers (which later became a recurring form within modern architecture, through the work of architects such as Le Corbusier or Oscar Niemeyer). The choice of this form in fact relies not on aesthetic concerns but on rationalist engineering principles. As calculated by the Russian engineer Vladimir Shukhov, whose first hyperboloid tower was completed in 1896, for a given diameter and height of a structure, as well as a given strength, this shape requires less material than any other form. Leonidov, together with other Constructivists, sought to rely upon state-of-the-art engineering to generate their designs, and often searched for the most materialeffective constructive solutions to implement them.

\section{The Cosmist Factor}

In a drawing representing a scheme of spatial organization of cultural services for his Club of a New Social Type project (1928), Leonidov opted for a fully black background upon which few circular colourful dots were surrounded by a series of thin white outlines, alluding obviously to planets and their orbits, and relating therefore more to a cosmic order than to the

8. A. Gozak and A. Leonidov, Ivan Leonidov: The Complete Works (London: Academy Editions, 1988), 38. 
architectural project at stake. Relating to the larger context of the universe-if not planning the universe itself-is what the esoteric philosophy of Cosmism, which emerged in the years that led to the Soviet Revolution of 1917, strived to do, with immortality as its ultimate goal. Cosmism, as a system of thoughts, was pioneered by the Russian philosopher Nikolai Fedorov (1829-1903), a librarian who published little during his lifetime, but whose magnum opus The Philosophy of the Common Task reached a larger audience of intellectuals after its posthumous publication in $1906 .{ }^{9}$ The ideas of Fedorov, who believed in science as a means to overcome the woes of the world, became very influential not only to revolutionary political thinkers, but also to the artistic avant-garde, including architects operating in the wake of the Revolution. His precepts were also developed into scientific studies by followers such as Tsiolkovsky, whose research contributed to the development of the Soviet space program.

If, as Boris Groys pointed, the initial technological drive of early Constructivism followed a desire to break with the traditions of the past, and therefore to embrace the chaos of the revolution, rather than to strive for the form of harmony Cosmist ideology aspired to ${ }^{10}$ the two strains of thought had a number of significant characteristics in common. Primarily, both were interested in social organization (and this is where it resonated with communist ideology), as the common task of shifting "from meteorology to meteorurgy" envisioned by Fedorov ${ }^{11}$ would necessitate a great deal of political unity. The fascination for potential technological developments is another point in common. Within these two movements, art was supposed to be subservient to the project of society as a whole, in accordance with the doctrine of Proletkult, a major cultural association which sought to promote the practice of nonprofessional artistry. As noted by Anatole Kopp, architecture in postRevolutionary Russia was only considered essential as a means to transform lifestyles and create a harmonious society through the planning of "social condensers." 12

The ultimate goal of immortality, in Fedorov's thought, necessitated space travel. By developing social unity, technological progress toward this goal could be sufficiently developed, and the colonization of the rest of the universe would provide the key to overcoming death, the Cosmists thought. Here, we can start to fathom a similarity in the type of technological projects both Cosmists and Constructivist tried to envision. Fedorov indeed makes a crucial parallel with architecture in one of his texts, precisely titled "Astronomy and Architecture." Seeing astronomy as the union of all sciences, and architecture

9. See: M. Hagemeister, "Russian Cosmism in the 1920s and Today," in The Occult in Russian and Soviet Culture (ed.) B. G. Rosenthal (Ithaca: Cornell University Press, 1997), 185-202.

10. B. Groys, "Introduction: Russian Cosmism and the Technology of Immortality," in Russian Cosmism (ed.) B. Groys (Cambridge, MA: EFlux-MIT Press, 2018), 3.

11. G. M. Young, The Russian Cosmists: The Esoteric Futurism of Nikolai Fedorov and his Followers (New York: Oxford University Press, 2012), 79.

12. A. Kopp. Ville et Révolution: Architecture et Urbanisme Soviétiques des Années Vingt (Paris: Points, 1972), 139. 
as that of all the arts, Fedorov in this text questions "why architecture cannot be called the application of a knowledge that is produced by astronomy.", "13

Fedorov was more specific when describing by which technological means should the space travel he called for be achieved. The aerostat-a dirigiblelike, lighter-than-air flying device — would be used at a global scale: "a massive configuration of lightning rod-aerostats," he wrote, would be utilized to redirect solar energy toward the Earth, so as to "alter the density of its new home, weaken the bonds of its gravity, giving rise in turn to the possibility of manipulating its celestial course through the heavens, rendering the planet Earth, in effect, a great electric boat." 14 For him, art was essential in this transformation, as it shared the goal of resurrection of destroyed beings, albeit at a symbolic level. Assimilating science to knowledge, and art to action, Fedorov asserted that "it is by that other discipline, the application of science, that the course not only of the Earth, but of whatever planets may prove moveable by the same methods, is to be directed," so as to turn them into "new dwellings."15

Despite the difference in scope between the Constructivist flying city schemes and Fedorov's project of "Earth Ship" - the former proposing to leave Earth, the latter suggesting to use it as a navigation device within the universe - the Cosmist idea of liberation from gravity resonates sharply with the weightlessness expressed in numerous Constructivist projects. This can be traced down to the very type of technology-oriented terminology used by these architects and planners. In particular, the use of the Greek prefix "aero-", denoting a relation to air and flight which was profusely used by Fedorov, appears in Khidekel's projects for an Aero-Club (1922), and for an Aero-City (Aerograd, ca. 1925), while Leonidov also used the term "Aerotram" to describe the means of transportation that leads to his Lenin Institute project. The student association called UNOVIS (Affirmers of the New Art), whose members benefitted from teachings on the cosmos by Malevich himself, even published a collection of articles under the very title Aero. ${ }^{16}$ Malevich's Black Square breakthrough painting, bordering figuration in an abstract manner by symbolizing the dark cosmos, was reportedly painted for the first time as part of a scenography for a futurist opera titled Victory Over the Sun in $1913,{ }^{17}$ which evoked a desired mastery of solar energy, on par with Cosmist ideas. Malevich also spent a great deal of his career imagining cosmic cities, and transmitting his precepts to his close student Khidekel, who literally titled one of his own drawings Cosmism: Suprematist Compositions in Space (1921). A recent interview with Khidekel's daughter-in-law Regina Khidekel further stresses this relationship: "Students of Malevich, including Lazar Khidekel," she said, "began to turn these forms into space stations. Structures and volumes

13. N. Fedorov, "Astronomy and Architecture," in Russian Cosmism (ed.) B. Groys (trans.) Ian Dreiblatt (Cambridge, MA: EFlux-MIT Press, 2018), 55.

14. Ibid, 56.

15. Ibid.

16. Khan-Magomedov, Pioneers of Soviet Architecture, 1987, 280.

17. Groys, Introduction: Russian Cosmism and the Technology of Immortality, 2018, 3. 
were perceived by them as the cosmic dwellings of future earthlings," sharing with Cosmist thought the idea of "resurrection of our ancestors, for whom these space colonies were designed." 18

Other traits of Constructivist projects, both representational and programmatic, point to the Cosmist imagination. For example, in Krutikov's competition design for the Columbus Monument in Santo Domingo (1929), a large sphere at the centre of the project, symbolizing the world, is surmounted by a very tall antenna, which in his rendering appears to capture energy from the sky in the form of a luminous beam, and to redistribute it towards the Earth from the same point, reminding clearly Fedorov's lightning rod-aerostat concept, aimed to perform the same function. At the very top of the Monument's antenna rests another smaller sphere, symbolizing the New World discovered by Columbus according to Krutikov, and alluding to the possible future conquest of other worlds, or planets, in Cosmist manner.

Leonidov's entry for the same competition likewise featured a very tall mast, and contained, in his typical penchant for programmatic invention, a meteorological station as well as scientific laboratories that included an "Institute for Interplanetary Communications," whose task, he explained, "is to solve the problem of interplanetary communications by means of the latest achievements of science and technology." ${ }^{19}$ Another allusion to Cosmist symbolism can be seen in Leonidov's competition entry for the new town of Magnitogorsk (1930), whose seminal aerial view - a montage that gives prominent place in its foreground to the photograph of a large dirigible (reminiscent of an aerostat) which flies in the same direction as his linear city scheme-appears to assign nearly equal value to architecture and infrastructure.

Lastly, and importantly, Cosmism and Constructivism shared a similar fate with the rise of Stalinism in the 1930s. Experimentation was progressively banned from architecture schools to make room for the form of neoclassicism that came along with socialist realism, while Constructivism was coined a form of "decadent bourgeois art." Accused of sabotage, Leonidov was sent to war in 1941 (and came back wounded in 1943). Most of the protagonists of Cosmism who had elaborated on Fedorov's ideas were likewise persecuted, and in a number of cases sent to labor camps or executed. Both movements were drastically put to an end, only to reappear decades later in Western media.

\section{Soviet Influence in the American Skyscraper}

If tall structures can be seen as an attempt to reach for the sky, they also involve, fatally, some form of connection to the ground, and the eclipse that Constructivist architecture has suffered between the 1930s and the 1960s has eventually constituted a wealth of inspiration to Western designers when this work was made available to them in the 1970s, particularly in America, the birthplace of

18. R. Khidekel, Khidekel i Goroda Budushhego, (Interv.) Dobryakova [18 August 2013.] Retrieved from https://art1.ru/2013/08/18/xidekel-i-goroda-budushhego-21083.

19. Gozak and Leonidov, Ivan Leonidov: The Complete Works, 1988, 68. 
the modern skyscraper. The Soviet skyscraper has surely been influenced by the American Beaux-Arts, ornamented towers erected in New York and Chicago around the beginning of the twentieth century, as suggested by Andrei Gozak in the reminiscence he pinpointed between a street-level photograph of a New York skyscraper in Eric Mendelsohn's Amerika, Bilderbuch Eines Architekten (1926) and Leonidov's perspective drawing of his Commissariat for Heavy Industry project seen from below. ${ }^{20}$ But this influence was essentially limited to the vertical typology of the skyscraper, and even that, as we have seen, was clearly challenged by the Constructivists' desire to couple the high-rise with the horizontal. Because of the typological reduction they operated in their works, one could argue that the influence of Russian avant-garde architects over the modern American skyscraper remains understated.

The experiment of the Lenin Institute of Librarianship, in this respect, can be further inspected. Its book shelves section, contained in the culminating, slender, rectangular tower of Leonidov's composition, could in fact be regarded, arguably, as the first modern skyscraper of this kind. Roughly thirty years before the completion of the design for the Seagram Building in Manhatttan by Ludwig Mies van der Rohe (who likely was well-verse in Leonidov's work, given his exposure to the cutting-edge architectural research and educational milieu of the Bauhaus) and Philip Johnson, he designed a tower that consisted of a mere box, completely devoid of ornaments, going as far as erasing the incidence of floor plates from the facades of the building. Louis Sullivan, theorizing the Beaux-Arts skyscraper at the end of the nineteenth century, famously advocated a view of the skyscraper as a tripartite organization which aimed to be reminiscent of a classical column, with a base, a shaft, and a capital. ${ }^{21}$ This traditional reference is radically rejected in Leonidov's scheme. What his design suggested was the sheer concept of reversibility, which also applies to the aesthetics of the Seagram Building and its derivatives in America and elsewhere.

The typology of the horizontal skyscraper, developed in the projects of Lissitsky, Khidekel, and Leonidov (with the Palace of Culture of the Proletarsky district of Moscow, and the planning of the new town of Magnitogorsk), also turned out to be reinterpreted more than once in architectural history (most notably by Italian, Dutch, and Japanese architects). Leonidov's project for Magnitogorsk in particular is interesting with respect to that topic. Embodying clearly the ideas of spatial conquest and equitable distribution of land, the project consisted of a 25kilometer continuous strip of housing and service buildings, laid out as a series of intermittent low-rise and high-rise squared quarters, and lined by a high-speed highway.

20. Ibid, 12.

21. L. H. Sullivan, "March. The Tall Office Building Artistically Considered," Lippincott's Magazine 57(Mar) (1896): 406. 
1.

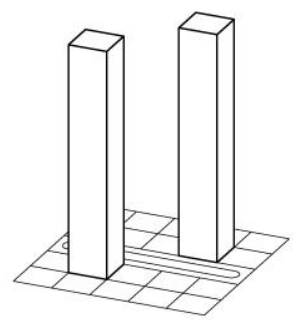

2.

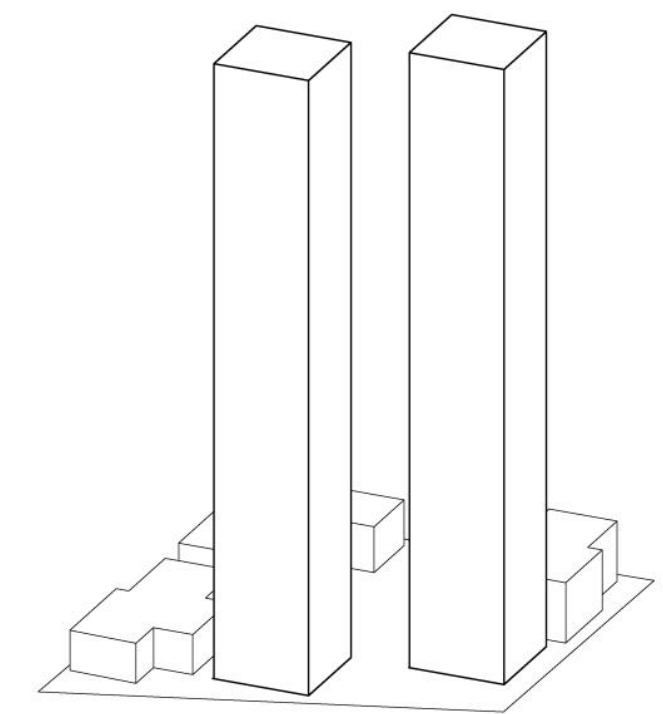

Figure 5. 1. Ivan Leonidov. Portion of a Planning Scheme for the New Town of Magnitogorsk, Ural Mountains, 1930 2. Minoru Yamasaki Associates and Emery Roth \& Sons. World Trade Center, New York, 1968-1973

Source: Drawing by Author.

What is of interest here is that one of the squared portions of his design, when looked at closely, contained a set of high-rises that resembled and preceded by over thirty years the design of Manhattan's World Trade Center by Minoru Yamasaki Associates and Emery Roth \& Sons (Figure 5). The American project replicated not only the idea of negation of the building as a single entity-since he designed two towers instead of one-but also the disposition of the two identical edifices in a checkerboard pattern within a gridded plan (paradoxically avoiding the notion of center itself). Aiming at establishing a symbolic relation with the planet as a whole, at the tip of the New World's most emblematic outpost, the towers of the World Trade Center were likewise based on the use of the square in terms of footprint. The parallel can be stretched to the very orientation of the two sets of twin towers, diagonally aligned with the North-South axis in both cases, and to the façade treatment, which in the two schemes attempted to conceal the presence of inner floors. Yamasaki, whom, like Leonidov, showed openness toward, and interest in, ornamented non-Western architecture (especially upon his return from a trip to India and the Far East in 1954, which influenced his designs), was likely aware of the Constructivist's linear city scheme, yet persistently sought to establish his full authorship of the World Trade Center project despite the collective nature of that enterprise. ${ }^{22}$

22. D. Salomon, "Divided Responsibilities: Minoru Yamasaki, Architectural Authorship, and the World Trade Center," Grey Room 7(Mar) (2002): 90-92. 


\section{Conclusions}

The history of American modern architecture often showcases the skyscraper as a mere product of capitalist forces: an almost logical result of either the pressures of the real estate market, or of local technological developments, such as elevators, generators, steel frame construction, water pumps, and air-conditioning systems. But one can argue that the modern skyscraper, as we know it, in its bland, common, repetitive, and gridded character has, in essence, more to do with the aesthetics of communism than with those of capitalism. The skyscraper, as a building type, relates to the notions of industry, regimentation, and uniformity, which have more to do with the socialist ideals of equitability (and, in a way, one could argue that the large Western corporations housed in skyscrapers have sought to emulate a communist type of organization) than with the individualistic credo of capitalism. And this neglect of personal specificities, this loss of the individual into communal space, is nowhere more deeply registered in architectural form than in the modern skyscraper.

As we have seen, the projects elaborated by Constructivist architects operating mostly during the second half of the 1920s, in themselves visions of the future attempting to reach far in both space and time, have found resonance in the design of buildings either planned or built decades later in Western countries. This phenomenon appears to closely relate to the literal meaning of the term "project," which involves, from an etymologic point of view, something that is essentially "thrown forth," requiring some form of flight prior to reaching the firm ground that architecture is known for sticking to. This is what the term "take-off" in the subtitle of this paper refers to. As an idea, this "project" finds itself developed into a theory in Fedorov's doctrine of "projectivism." 23 Paramount in his Cosmist philosophy, "projectivism" advocated the regulation of nature, its domestication by artificial means, taking to its extreme modernity's dichotomy between culture and nature, which the form of the skyscraper most directly represents.

In his 1924 Suprematist manifesto Unovis, Malevich wrote: "The new dwellings of man lie in space. The Earth is becoming for him an intermediate stage; accordingly airfields must be built suited to the aeroplane, that is to say without columnar architecture." 24 Around that time Malevich also produced his famous photomontage of a drawn architecton (consisting of sheer white blocks interpenetrating each other) pasted against the photographed backdrop of Manhattan's skyline - as if parachuted into foreign territory. This radical vision, which contrasted not only with the form of the Beaux-Arts high-rises in the background, but also with the market-driven pyramidal type of skyscraper propounded by New York architects such as Raymond Hood or Hugh Ferris in the 1920s, serves as an indication that he possibly foresaw the virtual landing of the Soviet skyscraper on Western ground.

23. Young, The Russian Cosmists: The Esoteric Futurism of Nikolai Fedorov and his Followers, 2012, 89.

24. K. Malevich, "Suprematist Manifesto Unovis," in Programs and Manifestos on $20^{\text {th }}$ Century Architecture (ed.) U. Conrads (trans.) Michael Bullock (Cambridge, MA: MIT Press, 1971), 87. 
It is argued here that the concept of weightlessness was instrumental in this projecting process, and that the philosophical precepts of Cosmism helped define the strategies adopted by Constructivists for the design of spatial settlements and representational aesthetics. Further, the meticulous detachment of programmatic elements into separate forms proposed in Leonidov's early projects can be regarded as both a facilitator of this phenomenon, and as a harbinger of the type of eclectic mixes of architectural programs which eventually characterized the modern Manhattan skyscraper.

Reflecting on the achievements of Russian avant-garde architects after a decade of intense productivity, El Lissitsky wrote in The Reconstruction of Architecture in the Soviet Union (1930): "The idea of the conquest of the substructure, the earthbound, can be extended even further and calls for the conquest of gravity as such." 25 Embedded in this ethereal concept of weightlessness lies an invocation of movement and transportability of architecture from one place to another, which can explain, in part, the adoption of Russian Revolutionary architecture by overseas designers. Had it yearned for groundedness, this transnational phenomenon would have been unlikely to take place.

\section{Bibliography}

Blanciak, F. "Revolutionary Objects: Pure Forms and Disorder in Ivan Leonidov's Work. Journal of Civil Engineering and Architecture 8, no. 2 (2014): 135-142.

Fedorov, N. "Astronomy and Architecture." In Russian Cosmism. Edited by B. Groys. Translated by Ian Dreiblatt. Cambridge, MA: EFlux-MIT Press, 2018, 55-58.

Gozak, A. and A. Leonidov. Ivan Leonidov: The Complete Works. London: Academy Editions, 1988.

Groys, B. "Introduction: Russian Cosmism and the Technology of Immortality." In Russian Cosmism. Edited by B. Groys. Cambridge, MA: EFlux-MIT Press, 2018.

Hagemeister, M. "Russian Cosmism in the 1920s and Today." In The Occult in Russian and Soviet Culture. Edited by B. G. Rosenthal. Ithaca: Cornell University Press, 1997, 185-202.

Herzog, J. and P. De Meuron. Treacherous Transparencies. New York: Actar, 2016.

Kaufmann, E. De Ledoux à Le Corbusier: Origine et Développement de l'Architecture Autonome. [From Ledoux to Le Corbusier: Origin and Development of Autonomous Architecture.] Translated by Guy Ballangé. Paris: La Villette, 2002.

Khan-Magomedov, S. O. Pioneers of Soviet Architecture: The Search for New Solutions in the 1920s and 1930s. Translated by A. Lieven. London: Thames and Hudson, 1987.

Khan-Magomedov, S. O. Georgii Krutikov: The Flying City and Beyond. Translated by C. Lodder. Barcelona: Tenov, 2015.

Khidekel, R. Khidekel i Goroda Budushhego. [Khidekel and Cities of the Future.] Interviewed by Dobryakova. [18 August 2013.] Retrieved from https://art1.ru/2013/ 08/18/xidekel-i-goroda-budushhego-21083.

25. E. Lissitsky, Russia: An Architecture for World Revolution (trans.) Eric Dluhosch (Cambridge, MA: MIT Press, 1970), 64. 
Kopp, A. Ville et Révolution: Architecture et Urbanisme Soviétiques des Années Vingt. [Town and Revolution: Soviet Architecture and City Planning in the 1920s.] Paris: Points, 1972.

Lissitsky, E. Russia: An Architecture for World Revolution. Translated by Eric Dluhosch. Cambridge, MA: MIT Press, 1970.

Malevich, K. "Suprematist Manifesto Unovis." In Programs and Manifestos on $20^{\text {th }}$ Century Architecture. Edited by U. Conrads. Translated by Michael Bullock. Cambridge, MA: MIT Press, 1971, 87-88.

Salomon, D. "Divided Responsibilities: Minoru Yamasaki, Architectural Authorship, and the World Trade Center." Grey Room 7(Mar) (2002): 86-95.

Sullivan, L. H. "March. The Tall Office Building Artistically Considered." Lippincott's Magazine 57(Mar) (1896): 403-409.

Terras, V. Vladimir Mayakovsky. Boston: Twayne Publishers, 1983.

Young, G. M. The Russian Cosmists: The Esoteric Futurism of Nikolai Fedorov and his Followers. New York: Oxford University Press, 2012. 